05

\title{
Влияние высокотемпературной термомеханической обработки В аустенитной области на микроструктуру и механические свойства малоактивируемой 12\%-ной хромистой ферритно-мартенситной стали ЭК-181
}

\author{
(C) Н.А. Полехина, ${ }^{1,2}$ И.Ю. Литовченко, ${ }^{1,2,9}$ А.Н Тюменцев, ${ }^{1,2}$ Д.А. Кравченко, ${ }^{2}$ В.М. Чернов, ${ }^{3}$ \\ М.В. Леонтьева-Смирнова ${ }^{3}$ \\ ${ }^{1}$ Институт фризики прочности и материаловедения СО РАН, \\ 634021 Томск, Россия \\ ${ }^{2}$ Национальный исследовательский Томский государственный университет, \\ 634050 Томск, Россия \\ ${ }^{3}$ АО Высокотехнологический НИИ неорганических материалов им. акад. А.А. Бочвара, \\ 123098 Москва, Россия \\ ฯ e-mail: litovchenko@spti.tsu.ru
}

(Поступило в Редакцию 7 июня 2016 г.)

\begin{abstract}
Исследовано влияние высокотемпературной термомеханической обработки с деформацией в аустенитной области на микроструктуру и механические свойства малоактивируемой $12 \%$-ной хромистой ферритномартенситной стали ЭК-181 (Fe-12Cr-2W-V-Ta-B). Такая обработка приводит к значительному, по сравнению с традиционным режимом обработки, увеличению плотности дислокаций, дисперсности и объемной доли наноразмерных частиц $\mathrm{V}(\mathrm{C}, \mathrm{N})$, и, как следствие, увеличению предела текучести при сохранении удовлетворительного запаса пластичности.
\end{abstract}

DOI: 10.21883/JTF.2017.05.44444.1916

\section{Введение}

Малоактивируемые (с быстрым спадом активности) 12\%-ные хромистые ферритно-мартенситные стали являются перспективными конструкционными материалами для активных зон и внутрикорпусных устройств ядерных и термоядерных энергетических реакторов $[1,2]$.

С целью расширения интервала рабочих температур этих сталей необходимо дополнительное повышение их высокотемпературной прочности (кратковременной и длительной) при сохранении необходимого запаса низкотемпературной пластичности. Решение этих задач связано с возможностью изменения и управления микроструктурой ферритно-мартенситных сталей с помощью термических и/или термомеханических обработок (ТО и/или ТМО). Среди таких обработок важное место занимает высокотемпературная термомеханическая обработка (ВТМО), включающая деформацию в аустенитной области. Перспективность ВТМО показана на 9\%-ных хромистых ферритно-мартенситных сталях [3-7]. Однако к 12\%-ным хромистым ферритно-мартенситным сталям эта обработка до сих пор не применялась.

Использование ВТМО связано с возможностью повышения эффективности дисперсного и субструктурного упрочнения за счет увеличения плотности дислокаций, объемной доли, выделяющихся во время обработки наноразмерных частиц $\mathrm{V}(\mathrm{C}, \mathrm{N})$ и формирования более мелкозернистой мартенситной структуры.

В настоящей работе показана эффективность ВТМО применительно в ферритно-мартенситной $12 \%$-ной хромистой малоактивируемой стали ЭК-181 (RUSFER-EK-181), разрабатываемой как конструкционный материал для активных зон ядерных и термоядерных энергетических реакторов $[1,2]$.

\section{Материал и методика эксперимента}

В качестве материала для исследований выбрана российская малоактивируемая 12\%-ная хромистая ферритно-мартенситная сталь ЭК-181 $(\mathrm{Fe}-12 \mathrm{Cr}-2 \mathrm{~W}-\mathrm{V}-\mathrm{Ta}-\mathrm{B})$, элементный состав которой представлен в табл. $1[1,2]$.

Традиционный режим термической обработки (ТТО) стали ЭК-181: закалка на воздух от $T=1100^{\circ} \mathrm{C}$ (выдержка в течение $1 \mathrm{~h}$ ) и отпуск при $T=720^{\circ} \mathrm{C}$ (выдержка в течение $3 \mathrm{~h}$ ).

ВТМО включала нагрев до $T=1100^{\circ} \mathrm{C}$ с выдержкой $1 \mathrm{~h}$, последующую горячую пластическую деформацию стали прокаткой до величины $\varepsilon \approx 30 \%$ за один проход (прокатный стан находился при комнатной температуре, температура образца на выходе из стана была не ниже $\approx 650^{\circ} \mathrm{C}$ ) и последующую закалку в воду. После ВТМО проводился отпуск при $T=720^{\circ} \mathrm{C}$ в течение $0.5-3 \mathrm{~h}$.

Структурные состояния и механические свойства образцов исследовали как непосредственно после ВТМО (без отпуска), так и после ВТМО с последующим отпуском.

Механические испытания осуществляли в вакууме $\sim 3 \cdot 10^{-3}$ Ра методом активного растяжения при температурах $T=20^{\circ} \mathrm{C}$ и $650^{\circ} \mathrm{C}$ с использованием образ- 
Таблица 1. Элементный состав стали ЭК-181 (wt.\%, основа Fe)

\begin{tabular}{c|c|c|c|c|c|c|c|c|c|c|c|c|c|c}
\hline $\mathrm{C}$ & $\mathrm{Cr}$ & $\mathrm{Mn}$ & $\mathrm{Mo}$ & $\mathrm{Nb}$ & $\mathrm{V}$ & $\mathrm{W}$ & $\mathrm{Ni}$ & $\mathrm{N}$ & $\mathrm{Si}$ & $\mathrm{Ta}$ & $\mathrm{Ce}$ & $\mathrm{Ti}$ & $\mathrm{B}$ & $\mathrm{Zr}$ \\
\hline 0.16 & 11.17 & 0.74 & 0.01 & 0.01 & 0.25 & 1.13 & 0.03 & 0.04 & 0.33 & 0.08 & 0.15 & 0.05 & 0.006 & 0.05
\end{tabular}
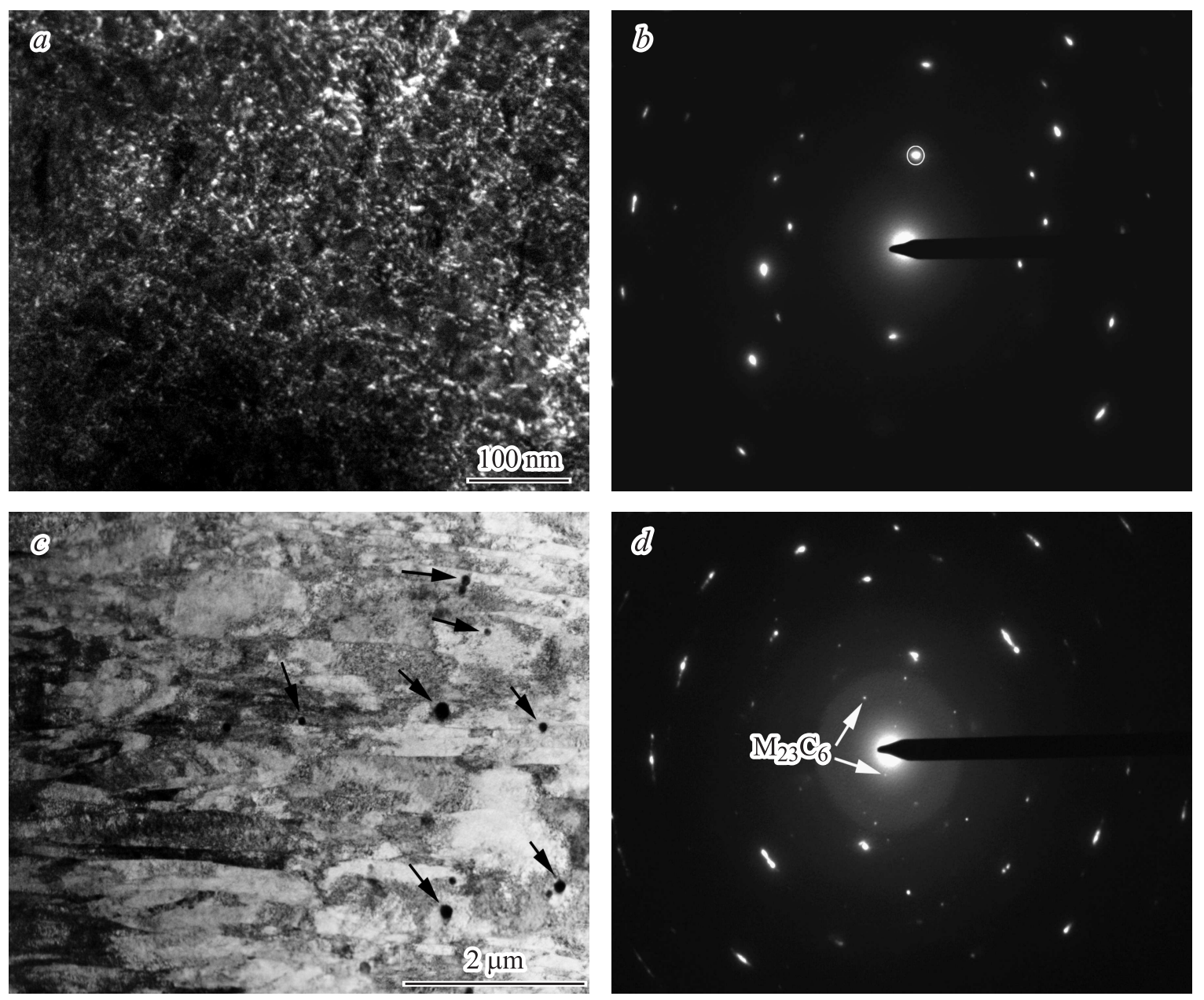

Рис. 1. Микроструктура стали ЭК-181 после ВТМО: $a$ - темнопольное изображение в рефлексе фазы V(C, N), совмещенном с рефлексом $\alpha$-Fe, $c$ - светлопольное изображение, $b, d-$ соответствующие микродифракционные картины. Стрелками отмечены частицы $\mathrm{M}_{23} \mathrm{C}_{6}$.

цов в форме двойных лопаток с размерами рабочей части $\sim 13 \times 2 \times 1 \mathrm{~mm}$. Структурные исследования проводили на просвечивающем электронном микроскопе Philips CM12 при ускоряющем напряжении $120 \mathrm{kV}$.

\section{Результаты исследований}

Электронно-микроскопическое исследование показало, что отличительными по сравнению с обычной закалкой в воду от $T=1100^{\circ} \mathrm{C}$ (выдержка $1 \mathrm{~h}$ ) особенностями микроструктуры стали после ВТМО являются:

1) увеличение в несколько раз объемного содержания наноразмерных частиц карбонитридной фазы $\mathrm{V}(\mathrm{C}, \mathrm{N})$ (рис. 1, $a, b)$;
2) значительное (от $\rho \sim 10^{11}$ до $\sim 10^{12} \mathrm{~cm}^{-2}$ ) повышение плотности дислокаций.

Первое является, на наш взгляд, следствием внесенной деформацией высокой плотности дислокаций в температурном интервале существования аустенита. Эти дислокации способствуют, во-первых, снижению барьера зарождения и критических размеров зародышей новой фазы; во-вторых, увеличению скорости роста частиц за счет повышения коэффициентов диффузии на дислокациях. Подчеркнем, что образование наноразмерных частиц $\mathrm{V}(\mathrm{C}, \mathrm{N})$ происходит в аустенитной фазе. В температурном интервале существования мартенсита (ниже $\sim 400^{\circ} \mathrm{C}$ ) это невозможно в связи с низкой диффузионной подвижностью карбидообразующих элементов. 
Таблица 2. Влияние режимов обработки на значения предела текучести и относительного удлинения стали ЭК-181 до разрушения

\begin{tabular}{c|c|c|c|c}
\hline \multirow{2}{*}{ Режим обработки } & \multicolumn{4}{|c}{ Температура испытаний } \\
\cline { 2 - 5 } & \multicolumn{2}{|c}{$T=20^{\circ} \mathrm{C}$} & \multicolumn{3}{|c}{$T=650^{\circ} \mathrm{C}$} \\
\cline { 2 - 5 } & $\sigma_{0.1}, \mathrm{MPa}$ & $\delta, \%$ & $\sigma_{0.1}, \mathrm{MPa}$ & $6.8-7.7$ \\
\hline Закалка в воду от $1100^{\circ} \mathrm{C}, 1 \mathrm{~h}$ & $1138-1190$ & $5.1-5.5$ & $400-417$ & $6.9-7.7$ \\
ВТМО & $1424-1486$ & $5.0-6.1$ & $430-435$ & $6.2-10.9$ \\
ТТО & $650-710$ & $6.0-6.6$ & $290-296$ & $14.1-15.0$ \\
ВТМО $+720^{\circ} \mathrm{C}, 1 \mathrm{~h}$ & $760-783$ & $5.0-7.0$ & $297-300$ & $9.5-11.7$ \\
$\mathrm{BTMO}+720^{\circ} \mathrm{C}, 0.5 \mathrm{~h}$ & $896-942$ & $8.6-9.0$ & $352-398$ & $10.5-13.2$
\end{tabular}

Объемная доля наноразмерных частиц после ВТМО не ниже, чем после ТТО, где они выделяются главным образом в процессе отпуска при $720^{\circ} \mathrm{C}, 3 \mathrm{~h}$. При этом практически все дислокации закреплены указанными частицами размерами не более $5 \mathrm{~nm}$. Помимо наночастиц $\mathrm{V}(\mathrm{C}, \mathrm{N})$ после такой обработки наблюдаются частицы $\mathrm{M}_{23} \mathrm{C}_{6}$ размерами от 50 до $\sim 150 \mathrm{~nm}$ преимущественно округлой формы (рис. $1, c, d$ ) и пластинчатые выделения $\mathrm{M}_{3} \mathrm{C}$ длиной до $\sim 200 \mathrm{~nm}$. Измельчения структуры мартенсита в результате ВТМО не обнаружено. Как и после обычной закалки, ширина мартенситных ламелей изменяется в пределах от 200 до $\sim 500 \mathrm{~nm}$ (рис. 1,c).

Последующий (после ВТМО) отпуск стали при $T=720^{\circ} \mathrm{C}$ в течение $3 \mathrm{~h}$ приводит к формированию структурного состояния со значительно более низкой, чем после ТТО, плотностью грубодисперсных карбидов $\mathrm{M}_{23} \mathrm{C}_{6}$ (рис. 2, $a, b$ ). Это связано с более интенсивным по сравнению с ТТО обеднением твердого раствора углеродом при образовании более высокой плотности наноразмерных частиц карбонитрида $\mathrm{V}(\mathrm{C}, \mathrm{N})$ уже в процессе ВТМО.

После указанного выше отпуска $\left(T=720^{\circ} \mathrm{C}, 3 \mathrm{~h}\right)$ происходит также коагуляция и уменьшение плотности наночастиц $\mathrm{V}(\mathrm{C}, \mathrm{N})$, тем не менее их дисперсность (размеры частиц не превышают $\sim 10 \mathrm{~nm}$, рис. 2,c) остается достаточно высокой. Кроме того, при сохранении высокой объемной доли отпущенного мартенсита наблюдается снижение внутренних напряжений и уменьшение плотности дислокаций от $\rho \sim 10^{11}-10^{12} \mathrm{~cm}^{-2}$ до $\sim(2-5) \cdot 10^{10} \mathrm{~cm}^{-2}$.

Исследование механических свойств (пределов текучести и относительного удлинения до разрушения) стали при комнатной температуре показало, что образование наноразмерных частиц в процессе предложенной термомеханической обработки совместно с высокой плотностью дислокаций и высокими внутренними напряжениями приводит к значительному (до $\sim 1486 \mathrm{MPa}$ ) увеличению предела текучести по сравнению с закалкой от $T=1100^{\circ} \mathrm{C}$ (табл. 2). При этом достигнуты макси- мальные прочностные свойства рассматриваемой стали. При повышенной $\left(T=650^{\circ} \mathrm{C}\right)$ температуре эффекты упрочнения менее значительны (табл. 2).

После ВТМО и отпуска при $T=720^{\circ} \mathrm{C}, 3 \mathrm{~h}$ указанные выше изменения микроструктуры (коагуляция наноразмерных частиц $\mathrm{V}(\mathrm{C}, \mathrm{N})$, уменьшение плотности дислокаций и внутренних напряжений) приводят примерно к двукратному при $T=20^{\circ} \mathrm{C}$ и полуторакратному при $T=650^{\circ} \mathrm{C}$ снижению предела текучести (табл. 2).

Сравнение с характеристиками прочности после ТТО (табл. 2) свидетельствует о том, что при комнатной температуре испытаний после ВТМО с последующим отпуском $720^{\circ} \mathrm{C}, 3 \mathrm{~h}$, эффекты упрочнения выше $(760-783 \mathrm{MPa})$, чем после ТТО $(650-710 \mathrm{MPa})$. При $T=650^{\circ} \mathrm{C}$ величина предела текучести $\left(\sigma_{0.1} \approx 300 \mathrm{MPa}\right)$ практически не зависит от режима обработки (ТTО или ВТМО + отпуск $720^{\circ} \mathrm{C}, 3 \mathrm{~h}$ ). Значительные (до $\sigma_{0.1} \approx 400 \mathrm{MПа)} \mathrm{эффекты} \mathrm{упрочнения} \mathrm{при} T=650^{\circ} \mathrm{C}$ могут быть достигнуты путем сокращения (до 0.5-1 h) времени отпуска (табл. 2), снижающего интенсивность субструктурного и дисперсного разупрочнения. При этом пластичность остается на достаточно высоком $(\delta \approx 9.5-13.2 \%)$ уровне.

Как видно, основным эффектом ВТМО является изменение объемной доли наноразмерных частиц $\mathrm{V}(\mathrm{C}, \mathrm{N})$, закрепляющих дислокационную структуру материала. В связи с этим оценим эффективность дисперсного упрочнения такими частицами. В [8] показано, что для стали ЭК-181 характерна обратная зависимость предела текучести от расстояний между наночастицами $\mathrm{V}(\mathrm{C}, \mathrm{N})$. Такое поведение характерно для механизма дисперсного упрочнения типа механизма Орована с огибанием частиц скользящими дислокациями. Величину упрочнения можно оценить по формуле $[9,10]$

$$
\Delta \sigma \approx G b / \lambda \text {. }
$$

Здесь $G \approx 86.5 \mathrm{GPa}$ - модуль сдвига стали ЭК-181 [1], $b \approx 0.25 \mathrm{~nm}$ - модуль вектора Бюргерса дислокаций, $\lambda \approx R(2 \pi / 3 f)^{1 / 2}-$ расстояние между 

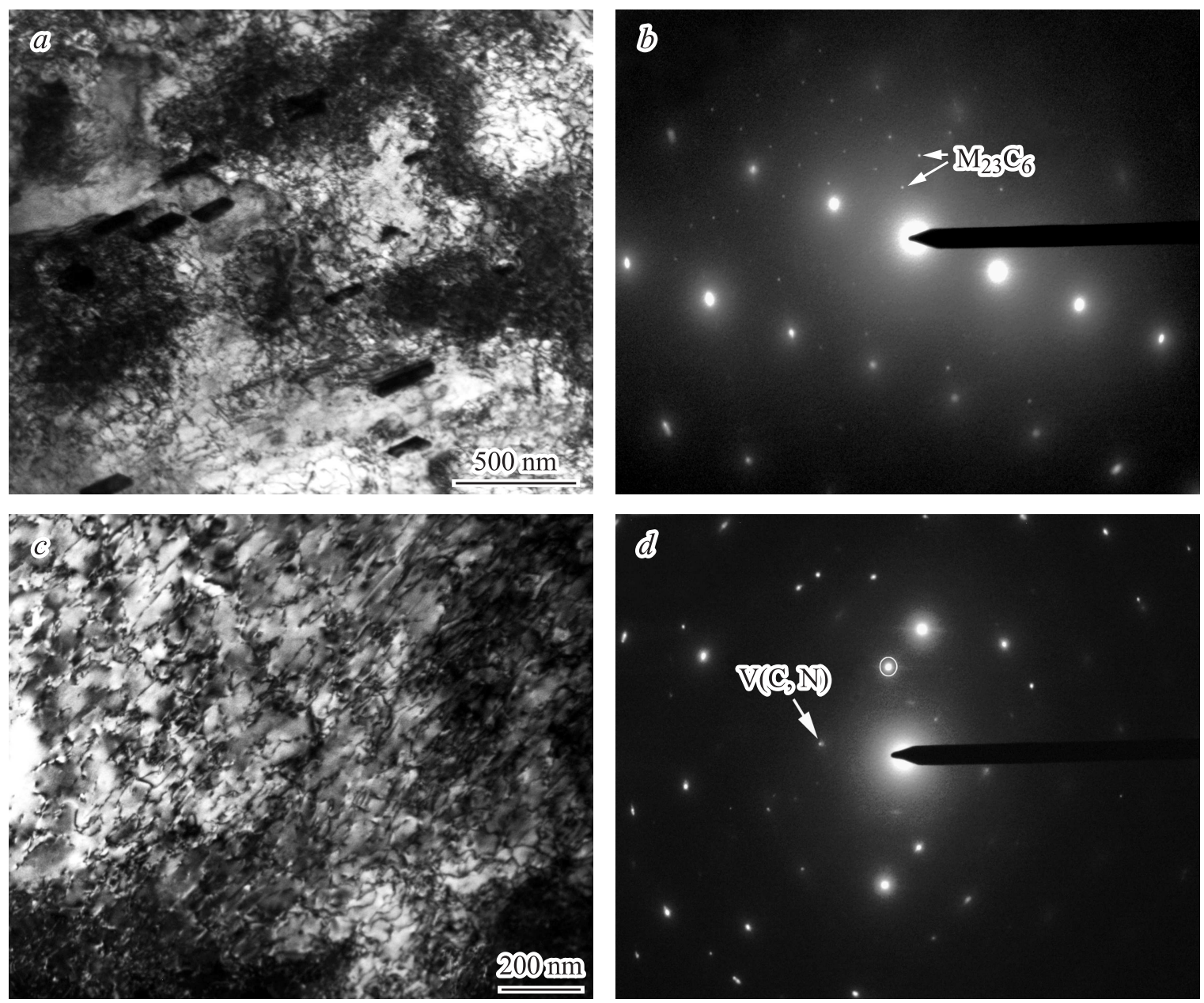

Рис. 2. Микроструктура стали ЭК-181 после ВТМО и отпуска при $T=720^{\circ} \mathrm{C}, 3 \mathrm{~h}: a-$ светлопольное изображение, $c-$ изображение в темном поле, $b, d-$ соответствующие микродифракционные картины.

Таблица 3. Теоретически рассчитанные значения напряжений Орована в стали ЭК-181 в зависимости от объемной доли и размеров частиц карбонитридной фазы

\begin{tabular}{c|c|c|c|c}
\hline \multirow{2}{*}{ Объемная доля, $f$} & \multicolumn{4}{|c}{ Размеры (диаметр $-2 R)$ частиц, $\mathrm{nm}$} \\
\cline { 2 - 5 } & 5 & 10 & 20 & 30 \\
\cline { 2 - 5 } & \multicolumn{4}{|c}{ Напряжение Орована, $\Delta \sigma, \mathrm{MPa}$} \\
\hline 0.015 & 746 & 370 & 186 & 124 \\
0.0075 & 526 & 263 & 132 & 88
\end{tabular}

краями частиц, $R$ - радиус частиц, $f-$ их объемная доля. Частицы считаются жесткими и не перерезаемыми скользящими дислокациями.

В табл. 3 приведены рассчитанные значения напряжения Орована для максимальной $(f \approx 0.015)$ объемной доли частиц $\mathrm{V}(\mathrm{C}, \mathrm{N})$ в предположении, что весь углерод и азот содержатся в указанной фазе, а также для случая, когда их объемная доля вдвое меньше. Из проведенных оценок видно, что дисперсное упрочнение частицами карбонитрида ванадия размерами $\sim 5-10 \mathrm{~nm}$ даже при относительно невысоком их объемном содержании может обеспечить наблюдаемое экспериментально повышение прочностных свойств стали (табл. 2).

Необходимо отметить, что представленные оценки не учитывают всей сложности и специфики процессов дисперсного упрочнения. Например, дисперсные частицы, выделяясь на дислокациях, границах и субграницах, вносят дополнительный вклад в зернограничное и субструктурное упрочнения [9]. Кроме того, оценки проведены без учета влияния температуры. Тем не менее они совместно с приведенными экспериментальными результатами наглядно иллюстрируют качественные возможности ВТМО для модификации гетерофазной структуры стали путем перераспределения углерода между карбидными фазами для создания структуры с высокой объемной долей наночастиц и соответственно высокой эффективностью дисперсионного упрочнения.

Из табл. 2 видно, что ВТМО, приводя к увеличению предела текучести при комнатной температуре, оказыва- 


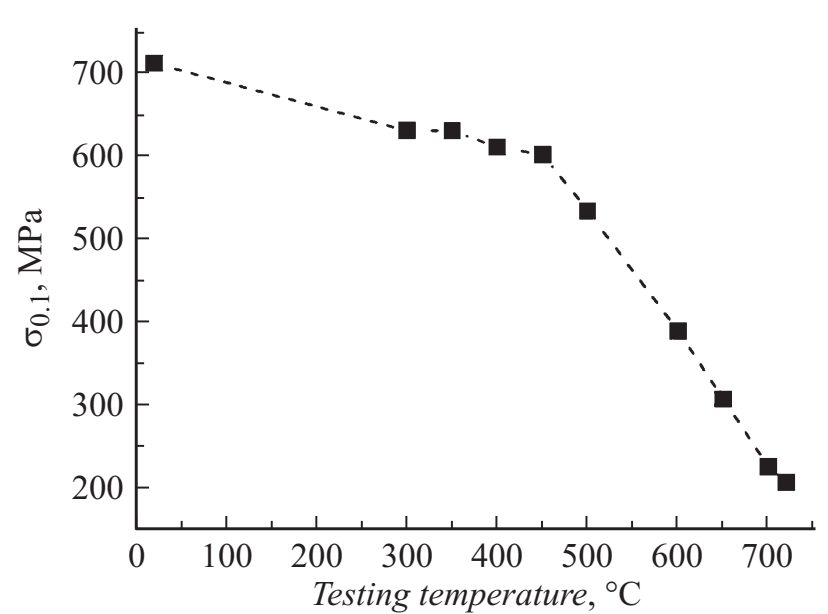

Рис. 3. Температурная зависимость предела текучести стали ЭК-181 после ТТО.

ет менее существенное влияние на характеристики кратковременной прочности при повышенных температурах $\left(T=650^{\circ} \mathrm{C}\right)$. Как показало исследование температурной зависимости предела текучести стали ЭК-181 (рис. 3), более чем двукратное снижение $\sigma_{0.1}$ при повышении температуры испытаний от комнатной до $T=650^{\circ} \mathrm{C}$ обусловлено сильной температурной зависимостью этой величины при $T \geq 450^{\circ} \mathrm{C}$. На наш взгляд, такая зависимость в значительной степени обусловлена уменьшением в этом интервале величины дисперсного упрочнения, связанным с активизацией процессов переползания дислокациями тормозящих их движение частиц $\mathrm{V}(\mathrm{C}, \mathrm{N})$.

Таким образом, одним из способов модификации микроструктуры и повышения механических свойств $12 \%$-ной хромистой ферритно-мартенситной стали ЭК-181 является предшествующая закалке пластическая деформация в температурном интервале существования аустенита. Такая деформация, во-первых, обеспечивает формирование в процессе ВТМО гетерофазной структуры с предельно высокой дисперсностью частиц карбонитрида ванадия $\mathrm{V}(\mathrm{C}, \mathrm{N})$ и соответственно более высокой эффективностью дисперсного упрочнения, во-вторых, предотвращает выделение грубодисперсных карбидов $\mathrm{M}_{23} \mathrm{C}_{6}$.

Отметим также, что наноразмерные частицы $\mathrm{V}(\mathrm{C}, \mathrm{N})$ могут оказывать положительное влияние на характеристики длительной высокотемпературной прочности стали путем закрепления дефектов (дислокаций, малоугловых границ) микроструктуры, обеспечивая ее более высокую термическую стабильность, в том числе в условиях ползучести.

\section{Заключение}

ВТМО стали ЭК-181 приводит к значительному по сравнению с обычной закалкой увеличению плотности дислокаций в мартенситной структуре, а также дис- персности и объемной доли наночастиц карбонитрида ванадия, выделяющихся непосредственно в процессе деформации в температурном интервале существования аустенита и последующей закалки. Предполагается, что важными факторами повышения объемной доли наночастиц $\mathrm{V}(\mathrm{C}, \mathrm{N})$ являются снижение барьера зарождения и критических размеров зародышей новой фазы и увеличение скорости роста частиц за счет возрастания коэффициентов диффузии карбидообразующих элементов на дислокациях.

Формирование структурных состояний с высокими значениями объемной доли наноразмерных частиц $\mathrm{V}(\mathrm{C}, \mathrm{N})$, плотности дислокаций и внутренних напряжений после ВТМО обеспечивает значительное (на $\approx 300 \mathrm{MPa}$ ) повышение значений предела текучести стали при комнатной температуре.

ВТМО с последующим отпуском при $T=720^{\circ} \mathrm{C}(1 \mathrm{~h})$ также приводит к существенному (по сравнению с ТTО) увеличению значений предела текучести стали как при комнатной (на $\left.\Delta \sigma_{0.1} \leq 290 \mathrm{MPa}\right)$, так и при повышенной $\left(T=650^{\circ} \mathrm{C} ;\right.$ на $\left.\Delta \sigma_{0.1} \leq 100 \mathrm{MPa}\right)$ температурах испытаний. При этом пластичность остается на достаточно высоком $(\delta \approx 10-13 \%)$ уровне.

Структурные исследования выполнены при финансовой поддержке РФФИ (научный проект № 16-38-00145 мол_а), исследование механических свойств проведено в рамках Программы фундаментальных научных исследований государственных академий наук на 2013-2020 г.

\section{Список литературы}

[1] Леонтьева-Смирнова М.В., Агабонов А.Н., Ермолаев Г.Н., Иолтуховский А.Г., Можсанов Е.М., Ревизников Л.И., Цвелев В.В., Чернов В.М., Буланова Т.М., Голованов В.Н., Островский 3.О., Шамардин В.К., Блохин А.И., Иванов М.Б., Козлов Э.Н., Колобов Ю.Р., Кардашев Б.К. // Перспективные материалы. 2006. № 6. С. 40-52.

[2] Chernov V.M., Leonteva-Smirnova M.V., Potapenko M.M., Budylkin N.I., Devyatko Yu.A., Ioltukhovskiy A.G., Mironova E.G., Shikov A.K., Sivak A.B., Yermolaev G.N., Kalashnikov A.N., Kuteev B.V., Blokhin A.I., Loginov N.I., Romanov V.A., Belyakov V.A., Kirillov I.R., Bulanova T.M., Golovanov V.N., Shamardin V.K., Strebkov Yu.S., Tyumentsev A.N., Kardashev B.K., Mishin O.V., Vasiliev B.A. // Nuclear Fusion. 2007. N 47. P. 839-848.

[3] Металловедение и термическая обработка стали: справочник в 3 т. / Под ред. М.Л. Бернштейна, А.Г. Рахштадта. М.: Металлургия, 1983. Т. 3. 215 с.

[4] Hollner S., Fournier B., Le Pendu J., Cozzika T., Tournié I., Brachet J.-C., Pineau A. // J. Nucl. Mater. 2010. Vol. 405. P. $101-105$.

[5] Hollner S., Piozin E., Mayr P., Caës C., Tournié I., Pineau A., Fournier B. // J. Nucl. Mater. 2013. Vol. 441. P. 15-23.

[6] Klueh R.L., Hashimoto N., Maziasz P.J. // J. Nucl. Mater. 2007. Vol. 367-370. P. $48-53$. 
[7] Tan L., Hoelzer D.T., Busby J.T., Sokolov M.A., Klueh R.L. // J. Nucl. Mater. 2012. Vol. 422. P. 45-50.

[8] Литовченко И.Ю., Полехина Н.А., Тюменцев А.Н., Астафурова Е.Г., Чернов В.М., Леонтьева-Смирнова М.В. // Вопросы атомной науки и техники. Серия термоядерный синтез. 2014. Т. 37. Вып. 1. С. 41-46.

[9] Гольдштейн М.И., Литвинов В.С., Бронфин Б.М. Металлофизика высокопрочных сплавов. М: Металлургия, 1986. $312 \mathrm{c}$.

[10] Хирт Джс., Лоте И. Теория дислокаций. М: Атомиздат, 1972. $600 \mathrm{c}$ 